\title{
Gelatin-based microspheres crosslinked with glutaraldehyde and rutin oriented to cosmetics
}

\author{
Fabiana Graziola1, Thalita Marcílio Candido ${ }^{1}$, Camila Areias de Oliveira ${ }^{1}$, Daniela D'Almeida \\ Peres $^{1}$, Michele Georges Issa ${ }^{1}$, Joana Mota ${ }^{2}$, Catarina Rosado ${ }^{2}$, Vladi Olga Consiglieri ${ }^{1}$, Telma Mary \\ Kaneko $^{1}$, Maria Valéria Robles Velasco ${ }^{1}$, André Rolim Baby ${ }^{*}$ \\ ${ }^{1}$ Department of Pharmacy, School of Pharmaceutical Sciences, University of São Paulo, São Paulo, SP, Brazil, ${ }^{2}$ CBios - \\ Centre for Research in Biosciences \& Health Technologies, Universidade Lusófona, Lisboa, Portugal
}

\begin{abstract}
Glutaraldehyde (GTA) has been extensively used as a gelatin crosslinking agent, however, new natural ones have been suggested as more biocompatible. Polyphenols are possible candidates and the flavonols, such as rutin (RUT), also exhibit potential synergism with sunscreens and antioxidant agents used in cosmetics. In this work, gelatin microspheres (M0) were obtained and crosslinked with GTA $10 \mathrm{mM}$ (MG) or RUT $10 \mathrm{mM}(\mathrm{MR})$, dissolved in acetone: $\mathrm{NaOH} \mathrm{0,01M} \mathrm{(70:30} \mathrm{v/v).} \mathrm{MG} \mathrm{exhibited} \mathrm{crosslinking}$ extent of $54.4 \%$. Gelatin, M0, MG and MR did not elicit any signs of skin damage, regarding the formation of erythema, the barrier function disruption and negative interference in the stratum corneum hydration. Oily dispersions containing M0, MG or MR, isolated or combined with benzophenone-3 or octyl methoxycinnamate, suggested that the microspheres, at a $5.0 \% \mathrm{w} / \mathrm{w}$, had no additional chemical or physical photoprotective effect in vitro. Crosslinking with RUT had occurred, but in a lower degree than GTA. Microspheres had not improved sun protection parameters, although, non-treated gelatin interfered positively with the SPF for both UV filters. The in vivo studies demonstrated that these materials had very good skin compatibility.
\end{abstract}

Uniterms: Protection solar/tests. Gelatin/microspheres/safety testing. Glutaraldehyde/safety testing. Flavonoids/Rutin/use in cosmetics. Natural products/use in cosmetics.

\section{INTRODUCTION}

Microspheres are microparticles in which a substance of interest is homogeneously dispersed within a polymer or a wax matrix, forming a monolithic system in which it is not possible to identify a distinct nucleus (Bresolin, Filho, 2003). Gelatin is a biodegradable natural polymer that can be used to produce microparticles. However, due to the aqueous solubility and limited mechanical and thermal properties of gelatin microparticles, improvements, such as crosslinking reactions, are necessary in order to provide the use in long term applications (Bigi et al., 2002; Hayashi, Tabata, 2011).

Crosslink reactions can be performed by chemical or physical medium and they cause structural changes that improve the gelatin mechanical strength and water

\footnotetext{
*Correspondence: A. R. Baby. Departamento de Farmácia. Faculdade de Ciências Farmacêuticas. Universidade de São Paulo. Av. Prof. Lineu Prestes, 580, Bloco 15, 05508-900 - São Paulo - SP, Brasil. E-mail: andrerb@usp.br. Phone number: +55 11 3091-2358
}

resistance (Ratanavaraporn et al., 2010). Glutaraldehyde (GTA) is the most used aldehyde as chemical crosslinking, but its toxicity concerns and flaws in materials like heart valves, that triggers the search for new crosslinking substances (Catalina et al., 2013). Flavonoids are polyphenolic and aromatic substances constituted by 15 carbon atoms. They have a diphenylpropane skeleton $\left(\mathrm{C}_{6} \mathrm{C}_{3} \mathrm{C}_{6}\right)$ with two benzene rings bonded to a pyran ring. Due to such structure, flavonoids are characterized as intrinsic agents of protection against ultraviolet radiation (UV) by acting as chemical filters that absorb in this wavelength range (Bruneton, 1991; Baby et al., 2009). Flavonoids are further divided into 13 classes according to the chemical structure, including flavonols (rutin, quercetin and mericitin). Because of its strong antioxidant activity, rutin is used in the prevention or treatment of venous or lymphatic insufficiency or capillary fragility and permeability, as well as, being used in the prevention of the damage caused by UV radiation (Velasco et al., 2008; Peres et al., 2016). Besides, flavonoids have been studied 
as a new alternative to chemical crosslinking agent for gelatin (Bigi et al., 2002; Strauss, Gibson 2004).

Chemical filters are substances that may be included in cosmetic formulations to protect the skin from damage caused by solar radiation. However, they can generate free radicals when exposed to sunlight and present problems related to photoallergenicity and skin irritation, as well as, photoinstability (Hanson, Gratton, Bardeen, 2006). Such scenario has driven the search for alternatives to minimize or eliminate these effects and there is a tendency to develop photoprotective cosmetic formulations with reduced concentration of chemical filters, but with high protection against UVA and UVB radiation, preferentially, with multifunctional benefits. The research of new photostable molecules for use in sunscreens are still performed extensively and, currently, we notice growing interest for the development of sunscreens based on natural products (Schlumpf et al., 2004; Tanaka, Setsuko, Utsumi, 1963; Oliveira et al., 2016).

In this research work, we investigated the use of the flavonoid rutin as an alternative to GTA for crosslinking gelatin microparticles. The good cutaneous compatibility of our samples was established by non-invasive methods and the physicochemical and functional properties of microparticles were determined to evaluate their applications as adjuvants for performance improvement of photoprotective dermocosmetic products.

\section{MATERIAL AND METHODS}

\section{Obtainment of gelatin microspheres}

Gelatin microspheres were obtained by emulsion polymerization method, using surfactant and solvent extraction (Tanaka, Setsuko, Utsumi, 1963; Ugwoke, Kinget, 1998). Gelatin (bovine, food grade, bloom 180 and mesh 30) was purchased from $\mathrm{NP}^{\circledR}$ (São Paulo, Brazil). An aqueous gelatin solution at $10.0 \% \mathrm{w} / \mathrm{w}(240.0 \mathrm{~g})$ was transferred by dripping to a mixture of mineral oil (560.0 $\mathrm{mL}$ ) and sorbitan monooleate (final concentration of $1.0 \%$ $\mathrm{w} / \mathrm{v})$ involving heating $\left(55.0^{\circ} \mathrm{C}\right)$ in a ceramic hot plate and mechanical agitation at $2400 \mathrm{rpm}$. The resulting emulsion was maintained under the conditions described previously for $15 \mathrm{~min}$ and then it was cooled to room temperature $\left(25.0^{\circ} \mathrm{C}\right)$ using water bath and $2400 \mathrm{rpm}$ agitation. Then, to enable the gelation of the sample, the emulsion was cooled between 10.0 and $15.0^{\circ} \mathrm{C}$ with an ice bath while stirring. After $30 \mathrm{~min}$, acetone $(400.0 \mathrm{~mL})$, at of $5.0^{\circ} \mathrm{C}$, was added dropwise with a burette to the emulsion and the mixture was stirred for another $30 \mathrm{~min}$, keeping the temperature at $10.0-15.0^{\circ} \mathrm{C}$, and then it was fractionated on $50.0 \mathrm{~mL}$ in plastic tubes to be centrifuged. After centrifugation ( $2 \mathrm{~min}, 3400 \mathrm{rpm}$, room temperature), the supernatant was discarded. To the amount of solid residue was added in an equal volume of acetone at $5.0^{\circ} \mathrm{C}$. The tubes were centrifuged again at $3400 \mathrm{rpm}$ for $2 \mathrm{~min}$. This procedure was repeated three times. After the last acetone washing, the solid residues were combined and dried at room temperature for at least 12 hours and the dry residue was sieved in 80 mesh sieve $(0.177 \mathrm{~mm}$ opening).

\section{Crosslinking of gelatin microspheres}

The crosslinking medium was consisted of acetone: $\mathrm{NaOH} 0.01 \mathrm{M}(70: 30 \mathrm{v} / \mathrm{v})$, in the proportion of $5.0 \mathrm{~g}$ of microspheres for each $100.0 \mathrm{~mL}$ of medium. The crosslinking agents were GTA (final concentration: $0.1 \%$ $\mathrm{w} / \mathrm{v}$, equivalent to $10.0 \mathrm{mM}$ ) and RUT (final concentration: $0.6 \% \mathrm{w} / \mathrm{v}$, equivalent to $10.0 \mathrm{mM}$ ) and we accomplished the crosslinking process for 4 hours with magnetic stirring at maximum speed at room temperature. After, the crosslinking medium was removed and the crosslinked microspheres were washed 5 times with acetone and agitated for 15 min with magnetic stirring at maximum speed. Subsequently, the crosslinked microspheres were kept in an open beaker to allow air drying for, at least, 12 hours. The microspheres were sieved at 80 mesh sieve.

\section{Appearance by scanning electron microscopy (SEM)}

Morphology of gelatin, M0, MG and MR was assessed by SEM. Dry and aqueous samples of gelatin used for obtaining the microparticles were observed and the microparticles were observed in triplicate. The observation of the samples was performed in scanning electron microscope Quanta 600 FEG, FEI ${ }^{\circledR}$ Company, (Hillsboro, OR, U.S.A.) in microscopic magnification of 150 to 50,000 times.

\section{Determination of extent of crosslinking}

There were added to $15.0 \mathrm{~mL}$ plastic tubes about $15.0 \mathrm{mg}$ of each sample. Then, to each tube was added 1.0 $\mathrm{mL}$ of $\mathrm{NaHCO}_{3}(4 \% \mathrm{w} / \mathrm{v})$ and $1.0 \mathrm{~mL}$ of TNBS $(0.5 \% \mathrm{w} / \mathrm{v})$. The tubes were transferred to a bath and kept for 2 hours in this condition. After, the TNBS reaction was stopped by adding $3.0 \mathrm{~mL}$ of $\mathrm{HCl}(6.0 \mathrm{~N})$ and the tubes were transferred to an ultrasonic bath, where they remained at $60.0^{\circ} \mathrm{C}$ for $90 \mathrm{~min}$, to ensure complete dissolution of samples. Subsequently, there were added $5.0 \mathrm{~mL}$ of purified water to each tube. The resulting solution was diluted to $1: 10$ and subjected to spectrophotometric 
analysis, in triplicate, at $345.0 \mathrm{~nm}$, using UV-VIS Spectrophotometer 600 Evolution $^{\circledR}$, Thermo Scientific (San Jose, CA, U.S.A.) (Sheu et al., 2001).

A standard curve of L-leucine with concentration range from 0.0 to $3.0 \mathrm{mM}$ was performed to measure free $\varepsilon$-amino groups in samples, which is equivalent to L-leucine groups (Gan, Cheng, Easa, 2009). The extent of crosslinking was calculated as shown in Equation 1.

Extent of crosslinking $=1-\frac{\left(\frac{\text { Absorbance crosslinked sample }}{\text { Mass crosslinked sample }}\right)}{\left(\frac{\text { Absorbance uncrosslinked sample }}{\text { Mass uncrosslinked sample }}\right)}$

\section{Determination of surface area}

Measurements of surface area and porosity were performed in gas adsorption analyzer $\mathrm{NOVA}^{\circledR} 2200 \mathrm{E}$, Quantachrome Corporation (Boynton Beach, FL, U.S.A.). Samples were subjected to freezing in liquid nitrogen for $20 \mathrm{~min}$ and then analyzed with ultra-pure nitrogen. For each sample, the isotherms were constructed utilizing multipoint method by collecting 30 points of adsorption and 20 of desorption. Results were generated by NOVA ${ }^{\circledR}$ $\mathrm{P}$-Win 9.0 program.

\section{Determination of true density}

The determination of the true density of the samples was performed in a helium gas pycnometer, Ultrapycnometer ${ }^{\circledR} 1000$, Quantachrome Corporation. Approximately, 1.5 to $4.0 \mathrm{~g}$ of each sample was subjected to three successive measurements of volume and density and, ultimately, the average density was determined.

\section{Determination of particle size distribution}

The determination of particle size distribution was done in laser diffraction particle size analyzer CILAS ${ }^{\circledR}$ 1090L (Orléans, France) by wet method. Sufficient amount of sample to obtain obscuration around $15 \%$ was dispersed in $50 \mathrm{~mL}$ of isopropyl alcohol and submitted to reading. Each sample was analyzed in triplicate in a range from 0.04 to $500 \mu \mathrm{M}$ per 100 classes.

\section{In vivo cutaneous compatibility assays}

Cutaneous compatibility was performed with 12 male and female volunteers, after informed oral and written consent. The procedures were in accordance with the ethical standards of the local responsible committee on human experimentation (Comissão de Ética da ULHT, Lisbon, Portugal) and with the Helsinki Declaration. Epicutaneous patches (Finn Chambers ${ }^{\circledR}$, Epitest) were applied in the volar forearms of the volunteers for $24 \mathrm{~h}$. Each patch had 5 chambers, containing each of the samples (gelatin, M0, MG and MR) at 10\% w/v in purified water, as well as, purified water as the negative control. Non-invasive measurements were conducted in each tested site: stratum corneum (SC) hydration was assessed with a Corneometer ${ }^{\circledR}$ CM825 (CK Electronics GmbH); skin barrier was probed with a Tewameter ${ }^{\circledR}$ TM 300 (CK Electronics GmbH). A Chroma Meter CR-300 (Minolta Camera, Japan) was used to quantify a possible increase in erythema by the parameter $a^{*}$ that reflects the red chromaticity. All measurements were performed in triplicate and using the CIE Lab system. The basal values were determined before patch application, and further measurements were made at 24 hours, 2 hours after its removal. To minimize the effect of inter-individual variability, the results were analyzed as the ratio between the values obtained after patch application and the basal values (Oliveira et al., 2015; Peres et al., 2016).

\section{In vitro efficacy determination}

Fifteen dispersions (formulations) were prepared with mineral oil, and mineral oil (and) polyethylene (Crodabase ${ }^{\mathbb{S}} \mathrm{SQ}$ ). There were added to dispersions: gelatin, M0, MG, MR, benzophenone-3 (BZ3) and octyl methoxycinnamate (OCT), alone or in combination, in order to obtain the sunscreen activity in vitro. Formulations followed the proportions shown in Table I.

For functional in vitro characterization of the samples, it was used diffuse reflectance spectrophotometer, equipped with integrating sphere, UV Transmittance Analyzer, Labsphere ${ }^{\circledR}$ UV-2000S (North Sutton). In order to mimic the surface properties of human epidermis, it was used a quartz plate substrate coated with Transpore ${ }^{\circledR}$ tape (Springsteen et al., 1999; Velasco et al., 2008)where human volunteers are subjected to potentially damaging and carcinogenic doses of ultraviolet radiation, has been the method of choice by regulatory agencies for determining the efficacy of sunscreens to protect humans from both sunburn (solar erythema.

Aliquots of the samples, accurately $0.75 \mathrm{mg} / \mathrm{cm}^{2}$, were applied uniformly in the form of film, in a circular motion on the surface of the substrate. The records of spectrophotometric absorbance values were performed in the wavelength range between 290.0 and $400.0 \mathrm{~nm}$, rate of progression of $1.0 \mathrm{~nm}$. The analysis was performed in triplicates for obtaining in vitro SPF (Springsteen et al., 1999; Velasco et al., 2008; Silva et al., 2013). 
TABLE I - Composition of the dispersions $(\% \mathrm{w} / \mathrm{w})$

\begin{tabular}{|c|c|c|c|c|c|c|c|c|c|c|c|c|c|c|c|c|c|c|c|c|}
\hline \multirow{2}{*}{ Components } & \multicolumn{20}{|c|}{$\% \mathrm{w} / \mathrm{w}$} \\
\hline & $\mathbf{A}$ & $\mathbf{B}$ & $\mathbf{C}$ & D & $\mathbf{E}$ & $\mathbf{F}$ & $\mathbf{G}$ & $\mathbf{H}$ & $\mathbf{I}$ & $\mathbf{J}$ & $\mathbf{K}$ & $\mathbf{L}$ & M & $\mathbf{N}$ & $\mathbf{O}$ & $\mathbf{P}$ & $\mathbf{Q}$ & $\mathbf{R}$ & $\mathbf{S}$ & $\mathbf{T}$ \\
\hline Mineral oil & 50,0 & 50,0 & 50,0 & 50,0 & 50,0 & 50,0 & 50,0 & 50,0 & 50,0 & 50,0 & 50,0 & 50,0 & 50,0 & 50,0 & 50,0 & 50,0 & 50,0 & 50,0 & 50,0 & 50,0 \\
\hline Crodabase $^{\circledR}$ SQ & 45,0 & 45,0 & 45,0 & 45,0 & 45,0 & 44,0 & 39,0 & 39,0 & 39,0 & 39,0 & 42,5 & 37,5 & 37,5 & 37,5 & 37,5 & 36,5 & 31,5 & 31,5 & 31,5 & 31,5 \\
\hline Gelatin & - & 5,0 & - & - & - & - & 5,0 & - & - & - & - & 5,0 & - & - & - & - & 5,0 & - & - & - \\
\hline M0 & - & - & 5,0 & - & - & - & - & 5,0 & - & - & - & - & 5,0 & - & - & - & - & 5,0 & - & - \\
\hline MG & - & - & - & 5,0 & - & - & - & - & 5,0 & - & - & - & - & 5,0 & - & - & - & - & 5,0 & - \\
\hline OCT & - & - & - & - & - & - & - & - & - & - & 7,5 & 7,5 & 7,5 & 7,5 & 7,5 & 7,5 & 7,5 & 7,5 & 7,5 & 7,5 \\
\hline
\end{tabular}

A to T: dispersions; (-): Raw material is not added; M0: Microspheres uncrosslinked; MG: microspheres crosslinked with glutaraldehyde; MR: microspheres crosslinked with rutin. BZ3: benzophenone-3; OCT: octyl methoxycinnamate

\section{Analysis of results}

Statistical analysis was performed using a Minitab (Version 16) software, with a significance level of $5.0 \%$ $(\alpha=0.05)$. Data were treated using one-way ANOVA followed by Tukey test for multiple comparisons.

\section{RESULTS AND DISCUSSION}

\section{Aspect of microspheres and yield of the processes of preparation and crosslinking}

Protein-based microspheres were developed with gelatin, a raw material that offers low cost, biocompatibility, biodegradability, low antigenicity and potential application in several dermocosmetic products (Nahar et al., 2008). The gelatin microspheres were slightly yellowish fine powder, unlike the coarse yellowish powder aspect of the gelatin, as raw material. After the crosslinking process, the powder aspect changed to slightly beige, when the GTA was the crosslinking agent and, to greenish yellow, when the RUT was the crosslinking agent.

The loss of, approximately, $25 \%$ in the process of obtaining microspheres can be mainly explained by the separation and removal of the low molecular weight gelatin in the supernatant of the emulsion when adding acetone, which is an agent that precipitates high molecular weight gelatin (Nahar et al., 2008). The loss observed between 15 and $18 \%$ in the crosslinking process of the microspheres can be explained mainly by the process of separation, by sieving and washes with acetone (Table II).

\section{Scanning electron microscopy}

It was observed that the gelatin used to obtain microspheres showed amorphous granules larger than
TABLE II - Microspheres process yield

\begin{tabular}{lc}
\hline Process & Process yield (\%) \\
\hline Obtaining & $74.8 \pm 8.5$ \\
Crosslinking with glutaraldehyde & $82.0 \pm 13.3$ \\
Crosslinking with rutin & $85.1 \pm 9.1$ \\
\hline
\end{tabular}

100 micron size (Figure 1). In increase of 5,000 times, it was possible to observe in detail the texture of gelatin suggesting compact and dense structure.

The gelatin microspheres obtained in this research work showed heterogeneity spherical shape and size (Figure 2). This observation confirmed the variation description of the particle size obtained by emulsion polymerization method using a surfactant and solvent extraction (Rabanel et al., 2009).

With a magnification of 50,000 times, it was possible to observe that the surface of all microspheres had a slight roughness, suggesting that crosslinking had no impact on surface morphology. This finding is contrary to that described by Choy et al. (2008), who observed expressive wrinkles on the surface of $\mathrm{MG}$ and described by Patel et al. (2006), who obtained microspheres with smooth surface (Choy et al., 2008). The use of $\mathrm{NaOH}$ and acetone, as a medium of crosslinking, may have led to differences in relation to the literature. The presence of agglomerates was greater in $\mathrm{MG}$ and MR than in $\mathrm{M} 0$.

\section{Extent of crosslinking}

The extent of crosslinking was determined by measuring the absorbance of the chromophore formed in the reaction of the free $\varepsilon$-amino groups of $\mathrm{M} 0, \mathrm{MG}$ and MR with 2,4,6-trinitrobenzenesulfonic acid (TNBS) with modifications (Sheu et al., 2001). The extent of 


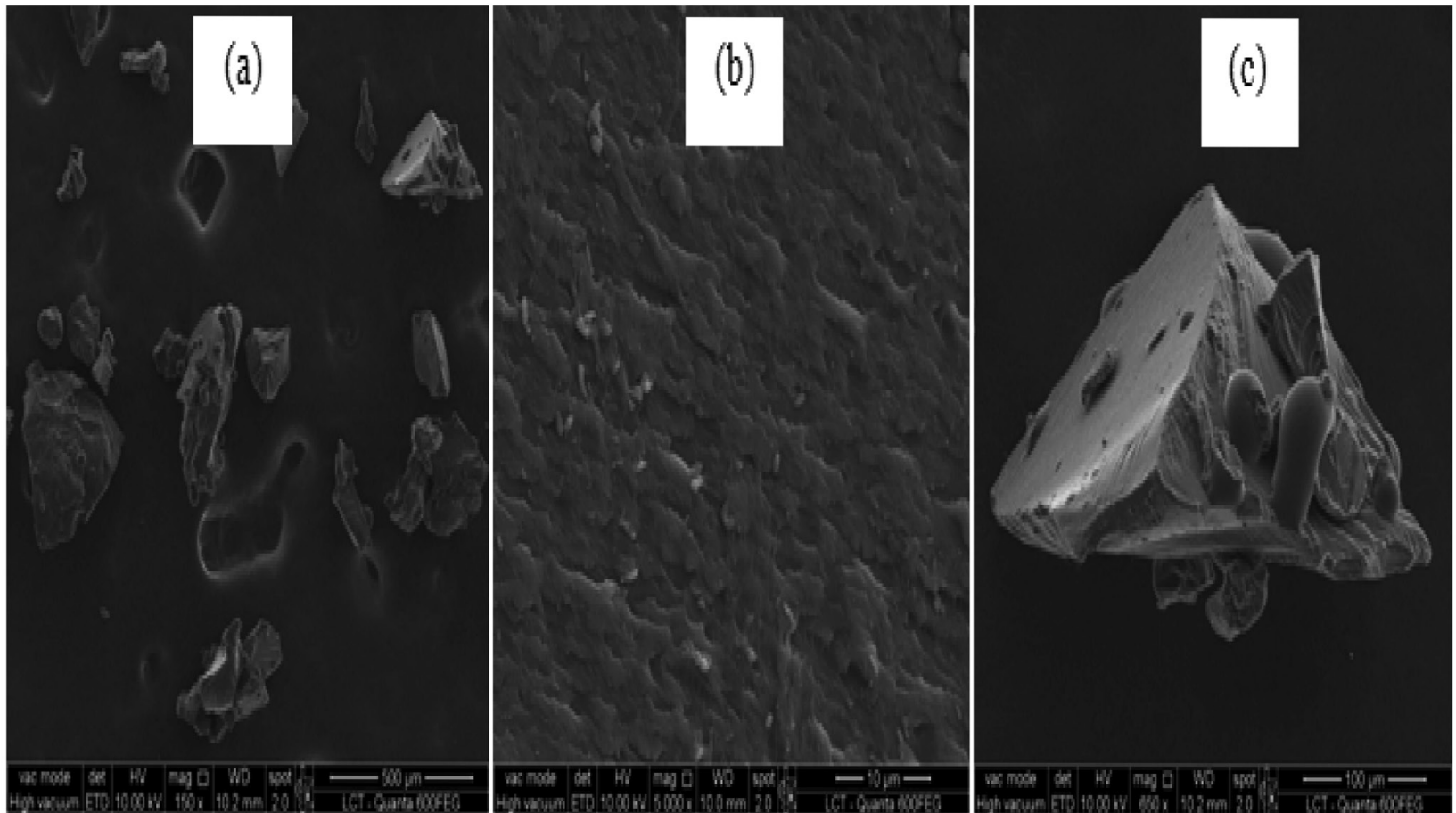

FIGURE 1 - SEM photomicrographs of gelatin (raw material) at a magnification of 150x (a), 5,000 x (b) and 650x (c).

(a)

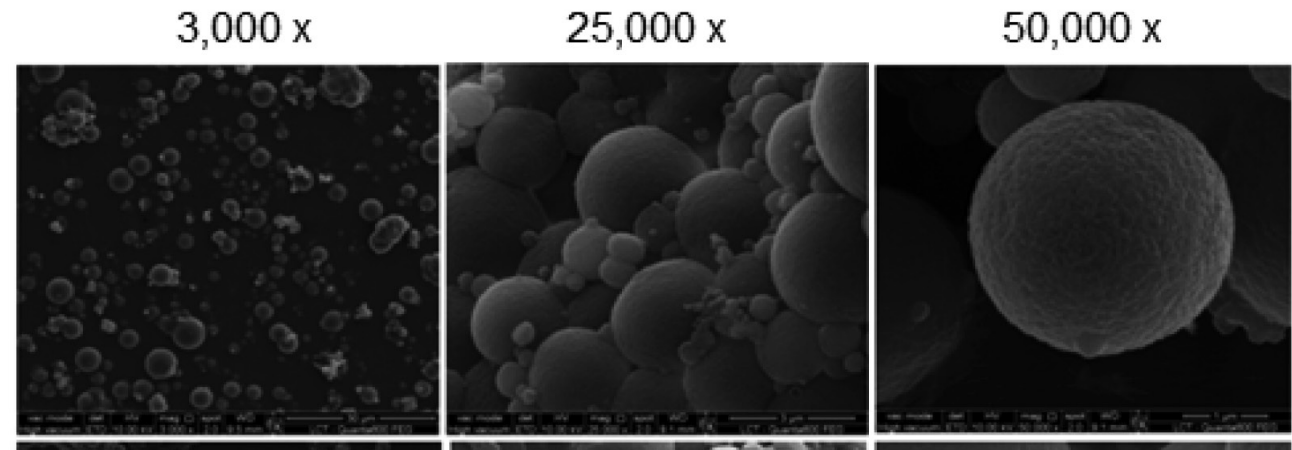

(b)

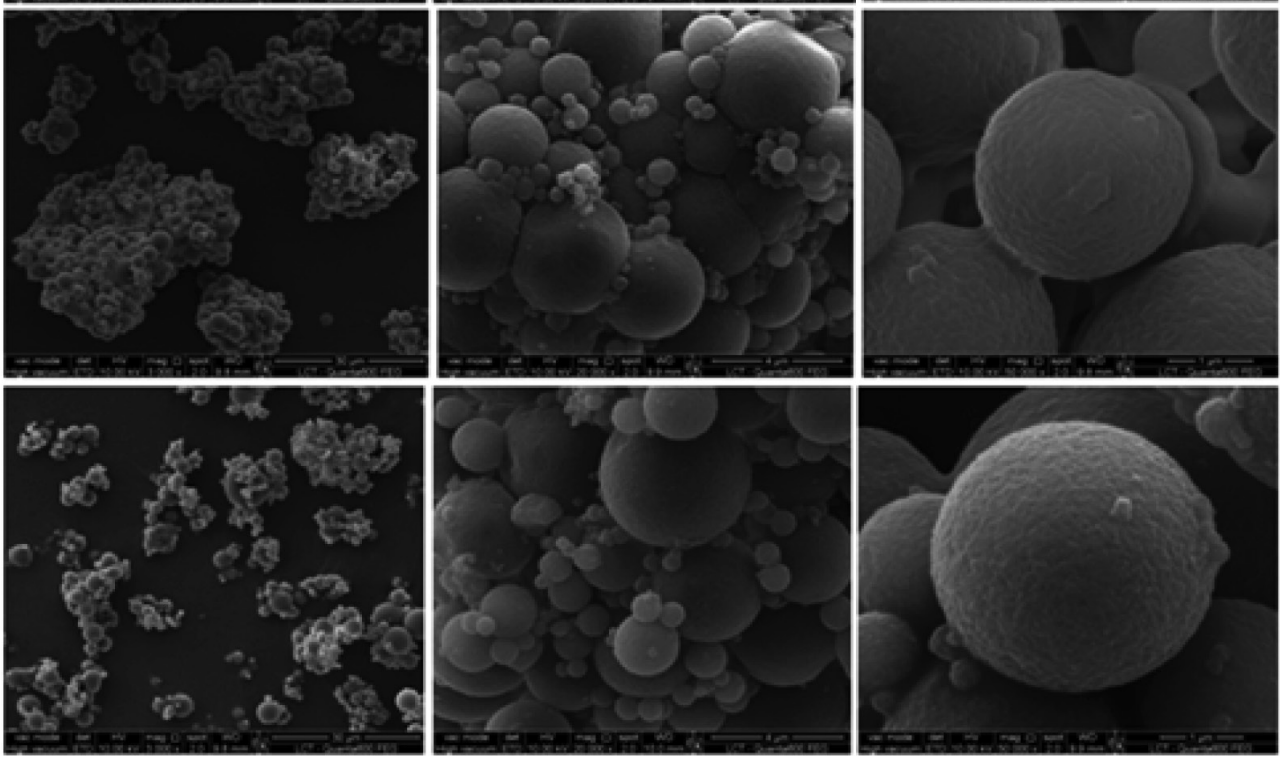

FIGURE 2 - SEM photomicrographs of M0 (a), MG (b) and MR (c) at a magnification of 3,000x, 25,000x and 50,000x. 
crosslinking was calculated in relation to non-crosslinked samples.

Reaction extent for gelatin and M0 were equal, demonstrating that the obtaining process of the microspheres had no impact on crosslinking of the free amino groups on the gelatin. Comparing to M0, the process of $\mathrm{MG}$ crosslinking resulted in the reduction of free amino groups with extent of $54.4 \%$. This value indicated that the free amino groups were successfully crosslinked when treated for $4 \mathrm{~h}$, under agitation in room temperature in a $\mathrm{NaOH} 0.01 \mathrm{M}$ and acetone solution containing GTA $10 \mathrm{mM}(0.1 \%)$. As exposed, this crosslinking occurred faster than the reaction described by Bigi et al. (2001) that registered an extent of crosslinking of $60.0 \%$ in gelatin films treated with 7.4 phosphate buffer containing GTA $0.05 \%$ for 24 hours at room temperature (samples were remained in rest). Regarding the values obtained with RUT reaction, it was observed that MR extent of crosslinking occurred quite discreetly (14.4\%).

\section{Surface area, Porosity and True Density}

Table III presents the results of surface area, pore volume, pore size and true density for gelatin, $\mathrm{M} 0, \mathrm{MG}$ and MR. Surface area and pore volume of MG were significantly lower than the values obtained for M0 and MR. However, this occurrence brought no changes to surface morphology of microspheres that can be identified by the SEM photomicrographs. The amount of pore sizes for all samples was in the range of mesoporosity classification (20-500 nm) (Teixeira, Coutinho, Gomes, 2001). No significant differences in this parameter were observed amongst M0, MG and MR. Values of true density for all samples showed no significant variations. This fact indicated that crosslinking with GTA influenced the results of surface area and pore volume, but it had no effect on true density of the powder.

\section{Particle size distribution and particle diameters}

The particle size distribution is presented in Figure 3. MR presented the smaller particle size distribution amplitude than M0 and MG. Diameter values at 10, 50, $90 \%$ and average diameter of gelatin, $\mathrm{M} 0, \mathrm{MG}$ and $\mathrm{MR}$ are presented in Table II.

Results presented that average diameters were higher in groups subjected to crosslinking (MG and MR), although, this value was only consistent with that one observed for surface area regarding the MG, which showed that the increase in particle diameter implied in its surface area reduction. Also, it has been reported that GTA is an effective crosslinker agent that provides stability and shape to gelatin microspheres by forming a network structure from the GTA aldehyde groups and the gelatin amino groups undergoing Schiff base reaction (Karthikeyan et al., 2013).

These results may indicate that, during the microspheres obtaining process, the washes with acetone, aiming at removing any oil residual, promoted deagglomeration of the particles, although, the crosslinking agents and some oily remained residual contributed to the highest average diameter for MG and MR.

\section{In vivo cutaneous compatibility assays}

According to the in vivo cutaneous biophysical properties established before (basal values) and 24 hours subsequently to the patch test, aqueous dispersions at $10.0 \% \mathrm{w} / \mathrm{v}$ of gelatin (non-treated raw material), $\mathrm{M} 0, \mathrm{MG}$ and MR did not elicit any signs of skin damage, regarding the formation of erythema (skin redness), disruption of the barrier function (increase in transepidermal water loss) and negative interference in the SC hydration, in comparison with the negative control (purified water). For all the variables, the ratio between the values after

TABLE III - Surface area, volume and pore sizes, true density, diameters of $10 \%, 50 \%, 90 \%$ and average diameter by laser diffraction of gelatin and gelatin microspheres

\begin{tabular}{|c|c|c|c|c|c|c|c|c|}
\hline Samples & $\begin{array}{c}\text { Surface area } \\
\left(\mathrm{m}^{2} / \mathrm{g}\right)\end{array}$ & $\begin{array}{c}\text { Pore size } \\
\text { (nm) }\end{array}$ & $\begin{array}{l}\text { Pore volume } \\
\left(\times 10^{-3} \mathbf{c m}^{3} / \mathbf{g}\right)\end{array}$ & $\begin{array}{c}\text { True density } \\
\left(\mathrm{g} / \mathrm{cm}^{3}\right)\end{array}$ & d (0.1) & $\mathrm{d}(\mathbf{0 . 5})$ & d (0.9) & $\begin{array}{c}\text { Average } \\
\text { diameter }\end{array}$ \\
\hline Gelatin & 0.8 & 2.6 & 1.1 & 1.4 & $104.5 \pm 1.3$ & $350.1 \pm 0.1$ & $467.1 \pm 0.1$ & $329.1 \pm 0.2$ \\
\hline M0 & $4.4^{\mathrm{a}} \pm 0.1$ & $3.0^{\mathrm{a}} \pm 0.1$ & $6.5^{\mathrm{a}} \pm 0.1$ & $1.6^{\mathrm{a}} \pm 0.0$ & $1.1^{\mathrm{a}} \pm 1.0$ & $6.4^{b} \pm 1.6$ & $29.4^{b} \pm 4.6$ & $11.2^{b} \pm 1.9$ \\
\hline MG & $1.8^{b} \pm 0.4$ & $3.4^{\mathrm{a}} \pm 0.1$ & $3.4^{b} \pm 0.1$ & $1.6^{\mathrm{a}} \pm 0.1$ & $2.7^{a . b} \pm 0.3$ & $18.1^{\mathrm{a}} \pm 2.0$ & $52.1^{\mathrm{a}} \pm 2.0$ & $23.6^{\mathrm{a}} \pm 1.6$ \\
\hline MR & $4.1^{\mathrm{a}} \pm 1.2$ & $3.0^{\mathrm{a}} \pm 0.3$ & $5.9^{\mathrm{a}} \pm 0.1$ & $1.6^{\mathrm{a}} \pm 0.1$ & $4.8^{\mathrm{b}} \pm 1.0$ & $18.4^{\mathrm{a}} \pm 0.6$ & $34.7^{\mathrm{a}} \pm 3.3$ & $19.7^{\mathrm{a}} \pm 1.6$ \\
\hline
\end{tabular}

Different letters in the same column represent statistically different results according to the ANOVA followed by Tukey test. M0: uncrosslinked gelatin microspheres; MG: gelatin microspheres crosslinked with GTA; MR: gelatin microspheres crosslinked with RUT. 

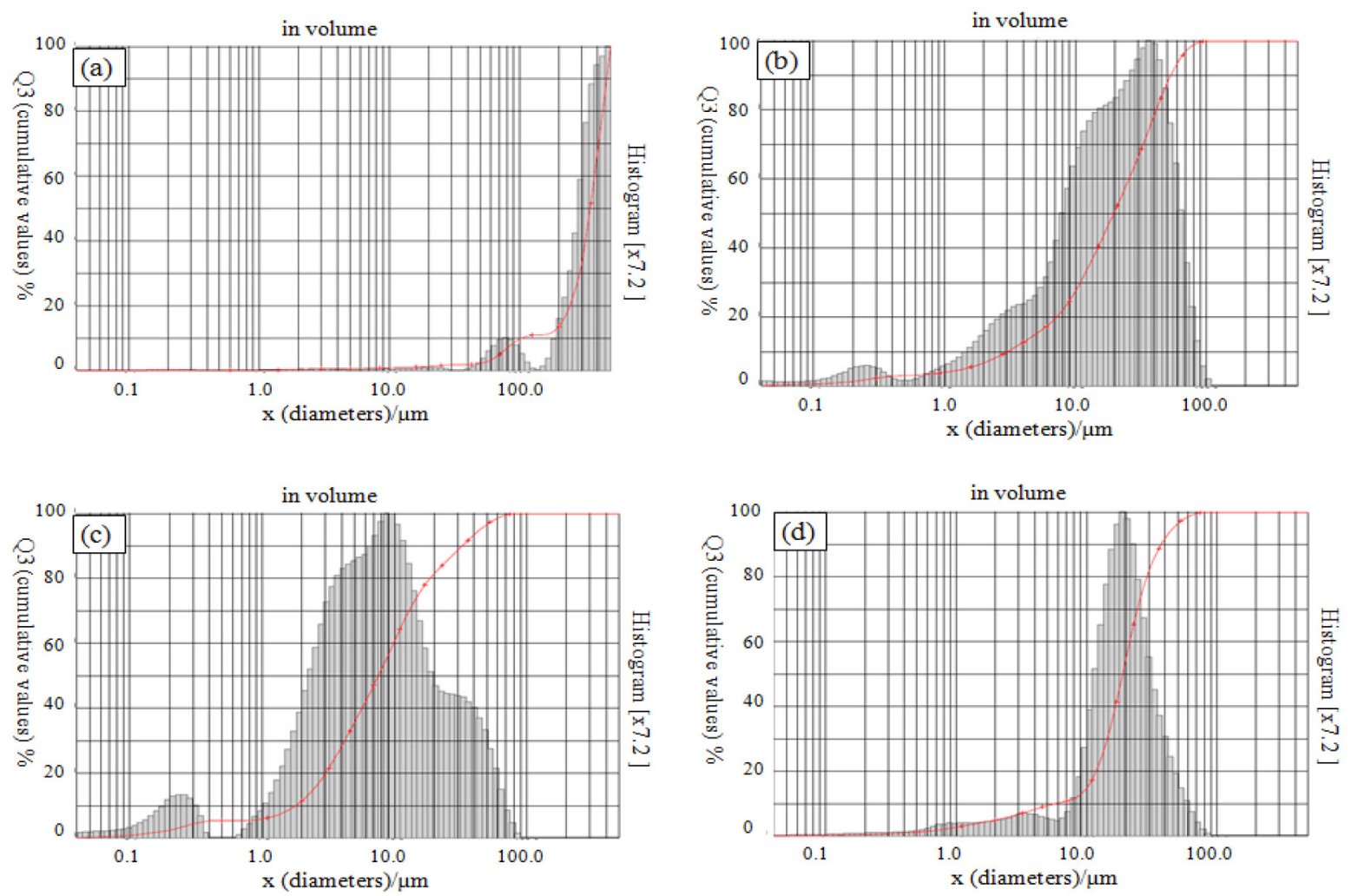

FIGURE 3 - Particle size distribution by laser diffraction of gelatin (a), M0 (b), MG (c) and MR (d).

the patch application and the basal values was, hence, close to 1 (Figure 4). The ratio was used to decrease the inter-individual variability impact (Oliveira et al., 2015).

\section{Photoprotective activity in vitro: SPF and protection against UVA}

Table IV presents the results of photoprotective efficacy in vitro for dispersions containing gelatin, M0, MG, MR, and/or UV filters, alone or in combination.

SPF values for dispersions containing gelatin (dispersion B), M0 (dispersion C), MG (dispersion D) or MR (dispersion $\mathrm{E}$ ) were equal to base dispersion (dispersion A), that presented value close to 1.0 (no antiUVB efficacy). All dispersions containing OCT and gelatin or microspheres (dispersions L, M, N and O) presented SPF values equal to or greater than 4.0. However, regarding to dispersions containing BZ3 and gelatin or microspheres, only the one containing gelatin (dispersion $\mathrm{G})$ presented SPF values equal to or greater than 4.0.

The dispersions containing gelatin and BZ3 or OCT (dispersions $G$ and $L$ ) had higher SPF values than the dispersions containing only one of these UV filters (dispersions $\mathrm{F}$ and $\mathrm{K}$ ), suggesting that the gelatin, as raw material, when combined with filters, showed good film formation and/or absorption in the UVB region that

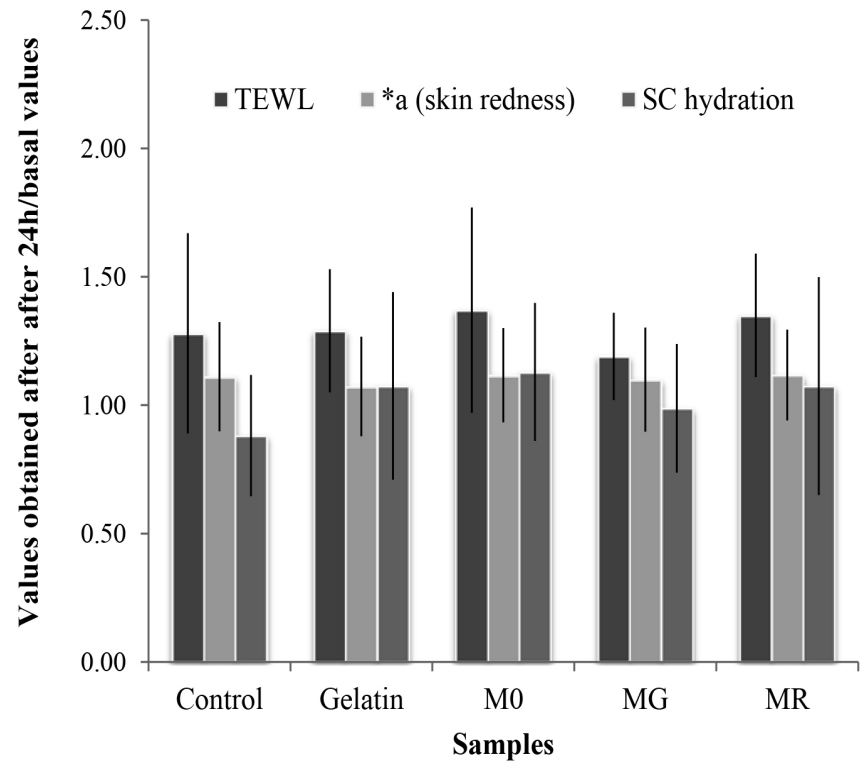

FIGURE 4 - In vivo cutaneous compatibility assays established by non-invasive methods (TEWL: transepidermal water loss; skin redness; and SC hydration: stratum corneum. M0: uncrosslinked gelatin microspheres; MG: gelatin microspheres crosslinked with GTA; MR: gelatin microspheres crosslinked with RUT.

contributed with the SPF improvement (dispersions $G$ and $\mathrm{L}$ ) and, interestingly, M0 did not achieve an enhanced 
TABLE IV - Photoprotective efficacy in vitro for dispersions containing gelatin and gelatin microspheres, and UV filters alone or in combination. Values were expressed as mean \pm standard deviation $(\mathrm{n}=3)$

\begin{tabular}{|c|c|c|c|}
\hline Dispersions & $\begin{array}{c}\text { Sun } \\
\text { protection } \\
\text { fator } \\
\text { (in vitro } \text { SPF) }\end{array}$ & $\lambda_{\mathrm{C}}(\mathrm{nm})$ & $\begin{array}{c}\mathbf{U V A} / \mathrm{UVB} \\
\text { ratio }\end{array}$ \\
\hline $\bar{A}$ & $1.0^{\mathrm{a}} \pm 0.1$ & $378.6^{a} \pm 9.6$ & $0.8^{\mathrm{a}} \pm 0.2$ \\
\hline B & $1.1^{\mathrm{a}} \pm 0.2$ & $383.0^{\mathrm{a}} \pm 10.0$ & $0.8^{\mathrm{a}} \pm 0.3$ \\
\hline $\mathrm{C}$ & $1.0^{\mathrm{a}} \pm 0.0$ & $377.5^{\mathrm{a}} \pm 20.0$ & $0.8^{\mathrm{a}} \pm 0.4$ \\
\hline $\mathrm{D}$ & $1.0^{\mathrm{a}} \pm 0.0$ & $386.0^{\mathrm{a}} \pm 6.6$ & $0.8^{\mathrm{a}} \pm 0.3$ \\
\hline $\mathrm{E}$ & $1.0^{\mathrm{a}} \pm 0.0$ & $374.6^{\mathrm{a}} \pm 12.4$ & $0.6^{\mathrm{a}} \pm 0.2$ \\
\hline $\mathrm{F}$ & $2.8^{\mathrm{b}} \pm 0.3$ & $354.7^{b} \pm 1.2$ & $0.5^{b} \pm 0.0$ \\
\hline G & $4.1^{\mathrm{c}} \pm 0.5$ & $354.5^{b} \pm 1.9$ & $0.5^{\mathrm{b}} \pm 0.0$ \\
\hline $\mathrm{H}$ & $3.7^{b . c} \pm 0.3$ & $356.1^{\mathrm{b}} \pm 1.7$ & $0.5^{b} \pm 0.0$ \\
\hline I & $3.3^{b . c} \pm 0.3$ & $354.9^{b} \pm 0.5$ & $0.5^{\mathrm{b}} \pm 0.0$ \\
\hline $\mathrm{J}$ & $3.8^{b . c} \pm 0.5$ & $356.3^{b} \pm 0.7$ & $0.5^{b} \pm 0.0$ \\
\hline K & $6.4^{\mathrm{d}} \pm 0.4$ & $328.3^{\mathrm{d}} \pm 2.2$ & $0.1^{\mathrm{d}} \pm 0.0$ \\
\hline L & $8.4^{\mathrm{e}} \pm 1.0$ & $327.3^{d} \pm 2.9$ & $0.1^{\mathrm{d}} \pm 0.0$ \\
\hline M & $6.8^{\text {d.e }} \pm 0.6$ & $328.7^{\mathrm{d}} \pm 3.4$ & $0.1^{\mathrm{d}} \pm 0.0$ \\
\hline $\mathrm{N}$ & $7.7^{\text {d.e }} \pm 0.3$ & $327.6^{\mathrm{d}} \pm 2.1$ & $0.1^{\mathrm{d}} \pm 0.0$ \\
\hline $\mathrm{O}$ & $7.3^{\text {d.e }} \pm 0.8$ & $328.0^{\mathrm{d}} \pm 3.7$ & $0.1^{\mathrm{d}} \pm 0.0$ \\
\hline $\mathrm{P}$ & $10.1^{\mathrm{f}} \pm 4.1$ & $351.3^{\mathrm{f}} \pm 1.7$ & $0.3^{\mathrm{f}} \pm 0.0$ \\
\hline Q & $16.2^{\mathrm{f}} \pm 3.4$ & $350.0^{\mathrm{f}} \pm 1.1$ & $0.3^{\mathrm{f}} \pm 0.0$ \\
\hline $\mathrm{R}$ & $10.7^{\mathrm{f}} \pm 1.1$ & $350.7^{\mathrm{f}} \pm 0.2$ & $0.3^{f} \pm 0.0$ \\
\hline S & $11.0^{\mathrm{f}} \pm 2.1$ & $351.2^{\mathrm{f}} \pm 1.2$ & $0.3^{f} \pm 0.0$ \\
\hline $\mathrm{T}$ & $12.4^{\mathrm{f}} \pm 1.4$ & $350.9^{\mathrm{f}} \pm 0.9$ & $0.4^{\mathrm{f}} \pm 0.0$ \\
\hline
\end{tabular}

Different letters in the same column represent statistically different results according to the ANOVA followed by Tukey test.

performance as the gelatin, even though, there was not the use of crosslinking agent.

According to our results, it may be suggested that M0, MG and MR performed discreetly film formation and with similar profile among them. It was supposed that the microspheres could develop a booster SPF activity by dispersing the UV radiation, considering the more rigid spherical structures achieved by the reaction with GTA and RUT, or by absorbing the UVB and UVA radiation, regarding the presence of the flavonoid. It is also allowed to suppose that the polymorph aspect of the gelatin, as rawmaterial, could have influenced the film formation more efficiently considering the arrangement of the irregular shape gelatin particles, that structured a thicker film, since the gelatin is not soluble at the oily vehicle adopted in this research. Still considering this property, the effect of MR could have been inhibited by two mechanisms: (i) rutin was inaccessible to absorb the UV radiation since it was bound to the gelatin through the crosslinking reaction; and (ii) rutin was not sufficient soluble at the oily vehicle, than it was not adequately free for exerting its UV absorbing property. Rutin is a natural compound that does not possess the tendency to permeate across the skin and it is a notable antioxidant that has been studied as sunscreen adjuvant with promising results. For example, our research group observed that an $\mathrm{O} / \mathrm{W}$ emulsion containing $0.1 \%$ rutin in association with $3.5 \%$ octyl methoxycinnamate and $1.0 \%$ benzophenone-3 developed a significant improvement of the in vitro sun protective properties in comparison with a similar preparation without the flavonoid (Baby et al., 2008; de Oliveira et al., 2015). Oliveira et al. (2015) additionally described the positive interaction of $0.1 \%$ rutin and $6.0 \% \mathrm{BZ} 3$ in an $\mathrm{O} / \mathrm{W}$ emulsion. Authors observed that the flavonoid contributed with the elevation of the in vitro SPF of 24 to 33. It is noteworthy to mention that the gelatin, M0, MG and MR concentrations were not suitable enough to interfere more positively with the efficacy parameters of sun protection.

Regarding $\lambda_{\mathrm{C}}$ (critical wavelength, $\mathrm{nm}$ ), only dispersions without filters (dispersions A, B, C, D and E) presented values of $\lambda_{\mathrm{C}}$ greater than $370 \mathrm{~nm}$. However, the average SPF values were approximately 1.0, indicating low protection against UVB radiation. The UVA/UVB ratio of dispersions containing OCT (dispersions $\mathrm{K}, \mathrm{L}$, $\mathrm{M}, \mathrm{N}$ and $\mathrm{O}$ ) was the lowest of all dispersions and it can be explained by UVB action, that is assigned to this chemical UV filter. Dispersions without filters showed no significant absorbance, indicating that gelatin and isolated microparticles did not develop substantial photoprotective action. In mixtures containing BZ3 and/or OCT, it was observed that there were no changes in the peak profiles due to the presence of gelatin or M0, MG or MR.

\section{CONCLUSION}

Physicochemical properties of MG and MR indicated that crosslinking method was more effective when the crosslinking agent was GTA and suggested that crosslinking occurred with RUT, however, to a lesser extent that would reinforce further researches to establish optimal conditions for the use of rutin as a potential substituent for GTA. The SPF analysis of dispersions containing M0, MG or MR, isolated or combined with chemical UV filters (benzophenone-3 and octyl methoxycinnamate) suggested that the microspheres (M0, MG or MR), at a $5.0 \% \mathrm{w} / \mathrm{w}$, had no additional chemical or physical photoprotective effect 
in vitro, and showed no influence on the estimated efficacy when combined with UV filters, that implies in formulation adjustments such as increasing of the gelatin microsphere concentrations and, as well as, use of new classes of UV filters. The in vivo studies demonstrated that these materials had very good skin compatibility.

\section{ACKNOWLEDGMENT}

Authors are greatly thankful to The State of São Paulo Foundation - FAPESP - (2012/04435-9 and 2012/19972-0). Authors thank Prof. Humberto Gomes Ferraz for his valuable support regarding the analysis of particle size distribution, surface area, pore volume, pore size and true density. Authors also thank Prof. Carlota de Oliveira Rangel-Yagui and Prof. Tânia Santos de Almeida for their kind supports.

\section{REFERENCES}

BABY, A.R.; HAROUTIOUNIAN-FILHO, C.A.; SARRUF, F.D.; TAVANTE-JÚNIOR, C.R.; PINTO, C.A.S.O.; ZAGUE, V.; ARÊAS, E.P.G.; KANEKO, T.M.; VELASCO, M.V.R. Estabilidade e estudo de penetração cutânea in vitro da rutina veiculada em uma emulsão cosmética através de um modelo de biomembrana alternativo. Rev.Bras. Ciênc. Farm., v.44, p.233-248, 2008.

BABY, A.R.; HAROUTIOUNIAN-FILHO, C.A.; SARRUF, F.D.; PINTO, C.A.S.O.; KANEKO, T.M.; VELASCO, M.V.R. Influence of urea, isopropanol and propylene glycol on rutin in vitro release from cosmetic semisolid systems estimated by factorial design. Drug Dev. Ind. Pharm., v.35, p.272-282, 2009.

BIGI, A.; COJAZZI, G; PANZAVOLTA, S.; RUBINI, K.; ROVERI, N. Mechanical and thermal properties of gelatin films at different degrees of glutaraldehyde crosslinking. Biomaterials, v.22, n.8, p.763-68, 2001.

BIGI, A.; COJAZZI, G; PANZAVOLTA, S.; RUBINI, K.; ROVERI, N. Stabilization of gelatin films by crosslinking with genipin. Biomaterials, v.23, n.24, p.4827-32, 2002.

BRESOLIN, T.M.B.; CECHINEL FILHO, V. Ciências farmacêuticas: contribuição ao desenvolvimento de novos fármacos e medicamentos. Itajaí: Editora da Universidade do Vale do Itajaí, 2003.

BRUNETON, J. Elementos de Fitoquímica y de Farmacognosia. Zaragoza: Acribia, 1991.
CATALinA, M.; ATTENBURROW, G.E.; COT, J.; COVINGTON, A.D.; ANTUNES, A.P.M. Influence of crosslinkers and crosslinking method on the properties of gelatin films extracted from leather solid waste. J. Appl. Polym. Sci., v.119, n.4, p.2105-2111, 2011.

CHOY, Y.B.; CHENG, F.; CHOI, H.; KIM, K.K. Monodisperse gelatin microspheres as a drug delivery vehicle: release profile and effect of crosslinking density. Macromol. Biosci., v.8, n. 8, p.758-765, 2008.

GAN, C.Y.; CHENG, L.H.; EASA, A.M. Assessment of crosslinking in combined cross-linked soy protein isolate gels by microbial transglutaminase and maillard reaction. J. Food Sci., v.74, n.2, p.141-146, 2009.

HANSON, K.M.; GRATTON, E.; BARDEEN, C.J. Sunscreen enhancement of uv-induced reactive oxygen species in the skin. Free Radical Biol. Med., v.41, n.8, p.1205-1212, 2006.

HAYASHI, K.; TABATA, Y. Preparation of stem cell aggregates with gelatin microspheres to enhance biological functions. Acta Biomater., v.7, n.7, 2797-2803, 2011.

KARTHIKEYAN, S.; RAJENDRA PRASAD, N.; GANAMANI, A.; BALAMURUGAN, E. Anticancer activity of resveratrol-loaded gelatin nanoparticles on NCI-H460 non-small cell lung cancer cells. Biomed. Prev. Nutr., v.3, n.1, p.64-73, 2013.

NAHAR, M.; MISHRA, D.; DUBEY, V.; JAIN, N.K. Development, characterization, and toxicity evaluation of amphotericin b-loaded gelatin nanoparticles. NanomedNanotechnol., v.4, n.3, p.252-261, 2008.

OLIVEIRA, C.A.; PERES, D.D.; GRAZIOLA, F.; BOUCHACRA, N.A.; ARAUJO, G.L.B.; FLORIDO, A.C.; MOTA, J.P.; ROSADO, C.; VELASCO, M.V.R.; RODRIGUES, L.M.; FERNANDES, A.S.; BABY, A.R. Cutaneous biocompatible rutin-loaded gelatin-based nanoparticles increase SPF of the association of UVA and UVB filters. Eur. J. Pharm. Sci., v.81, p.1-9, 2016.

OLIVEIRA, C.A.; PERES, D.D.; RUGNO, C.M.; KOJIMA, M.; PINTO, C.A.S.O.; CONSIGLIERI, V.O.; KANEKO, T.M.; ROSADO, C.; MOTA, J.; VELASCO, M.V.R.; BABY, A.R. Functional photostability and cutaneous compatibility of bioactive UVA sun care products. J. Photoch. Photobio. B, v.148, p.154-159, 2015. 
PATEL, M.; JAIN, S.K.; YADAV, A.K.; GOGNA, D.; AGRAWAL, G.P., Preparation and characterization of oxybenzone-loaded gelatin microspheres for enhancement of sunscreening efficacy. Drug Deliv., v.13, n.5, p.323-330, 2006.

PERES, D.D.; OLIVEIRA, C.A.; COSTA, M.S.; TOKUNAGA, V.K.; MOTA, J.P.; ROSADO, C.; CONSIGLIERI, V.O.; KANEKO, T.M.; VELASCO, M.V.R.; BABY, A.R. Rutin increases critical wavelength of systems containing a single UV filter and with good skin compatibility. Skin Res. Technol., v.22, p.325-333, 2016.

RABANEL, J.M.; BANQUY, X.; ZOUAOUI, H.; MOKHTAR, M.; HILDGEN, P. Progress technology in microencapsulation methods for cell therapy. Biotechnol. Progr., v.25, n.4, p.946-963, 2009.

RATANAVARAPORN, J .; RANGKUPAN, R.; JEERATAWATCHAI, H.; KANOKPANONT, S.; DAMRONGSAKKUL, S. Influences of physical and chemical crosslinking techniques on electrospun type a and b gelatin fiber mats. Int. J. Biol. Macromol., v.47, n.4, p.431-438, 2010.

SCHLUMPF, M.; SCHMID, P.; DURRER, S.; CONSCIENCE, M.; MAERKEL, K.; HENSELER, M.; GRUETTER, M.; HERZOG, I.; REOLON, S.; CECCATELLI, R.; FAASS, O.; STUTZ, E.; JARRY, H.; WUTTKE, W.; LICHTENSTEIGER, W. Endocrine activity and developmental toxicity of cosmetic uv filters - an update. Toxicology, v.205, n.1-2, p.113-122, 2004.

SHEU, M.T.; HUANG, J.C.; YEH, G.C.; HO, H.O. Characterization of collagen gel solutions and collagen matrices for cell culture. Biomaterials, v.22, n.13, p.17131719,2001
SILVA, D.G.; SARRUF, F.D.; OLIVEIRA, L.C.D.; ARÊAS, E.P.G.; KANEKO, T.M.; CONSIGLIERI, V.O.; VELASCO, M.V.R.; BABY, A.R. Influence of particle size on appearance and in vitro efficacy of sunscreens. Braz. J. Pharm. Sci., v.49, n.2, p.251-261, 2013.

SPRINGSTEEN, A.; YUREK, R.; FRAZIER, M.; CARR, K.F. In vitro measurement of sun protection factor of sunscreens by diffuse transmittance. Anal. Chim. Acta, v.380, n.2-3, p.155-164, 1999.

STRAUSS, G.; GIBSON, S.M. Plant phenolics as cross-linkers of gelatin gels and gelatin-based coacervates for use as food ingredients. Food Hydrocolloid, v.18, n.1, p.81-89, 2004.

TANAKA, N.; SETSUKO, T.; UTSUMI, I. A new oral gelatinized sustained-release dosage form. J. Pharm. Sci., v.52, n.7, p.664-667, 1963.

TEIXEIRA, V.G.; COUTINHO, F.M.B., GOMES, A.S. Principais métodos de caracterização da porosidade de resinas à base de divinilbenzeno. Quim. Nova, v.24, n.6, p.808-818, 2001.

UGWOKE, M.I.; KINGET, R. Influence of processing variables on the properties of gelatin microspheres prepared by the emulsification solvent extraction technique. $J$. Microencapsul., v.15, n.3, p.273-281, 1998.

VELASCO, M.V.R.; SARRUF, F.D.; SALGADO-SANTOS, I.M.; HAROUTIOUNIAM-FILHO, C.A.; KANEKO, T.M.; BABY, A.R. Broad spectrum bioactive sunscreens. Int. J. Pharm., v.1/2, p.50-57, 2008.

Received for publication on $04^{\text {th }}$ January 2016 Accepted for publication on $13^{\text {th }}$ September 2016 